\title{
The Influence of Country of Origin Cues on Product Evaluation: Evidence from Swiss and German Consumers
}

\author{
Olga Visbal ${ }^{1^{*}}$, Herrera-Mendoza Ketty ${ }^{2}$, Erick Orozco-Acosta ${ }^{3}$, Markus Herzberg $^{4}$
}

\begin{abstract}
This study aimed to investigate the influence of visual symbols on the perception and evaluation of two fictitious products as well as the effect of demographic characteristics (nationality) on consumers' evaluations. A sample of 373 participants was split into two groups and two experimental conditions (products with Swiss symbols and products without Swiss symbols). One group of participants rated the packaging without a Swiss flag and the other one rated the same packaging with a Swiss flag. A semantic differential scale and the Self-Assessment Manikin (SAM) were used to assess attitudes toward the products. Results confirm that there are differences between the two independent groups and that nationality has an effect on product perception and evaluation. Visual symbols such as a country flag can lead to a better product perception and evaluation. Finally, implications for research are discussed.
\end{abstract}

Keywords: visual symbols; country of origin; Swiss symbols; product evaluation; product perception.

Submitted: March $26^{\text {th }} 2017$ / Approved: Jun $30^{\text {th }} 2017$

\section{Introduction}

Although the Country of origin (COO) has been widely investigated in the past years, it is still a concern in international marketing (Koschate-Fischer, Diamantopoulos \& Oldenkotte, 2012). COO cues play a significant role in product evaluation (Maheswaran \& Chen, 2006). According to the cue utilization theory, consumers make their inferences about the quality of a product based on many cues like color, price, packaging, and country of origin or production (Jacoby, Olson \& Handdock 1971). Thus, c ountry of o rigin symbols also known as "made in" labeling (O'Mara, Cort \& Palin, 2011) are used in marketing and branding of products to differentiate themselves and to associate the products with positive attributes (Brodie \& Sharma, 2011). Consumers presume traits of the product based on the stereotypes associated with the country of origin and the experiences with other products of that country (Dagger \& Racit, 2011). Consistent with this, research on this topic confirms that many consumers make product evaluation and purchase decisions based on country of origin cues (Miller, 2011). For example, German brands with the "Made in Germany" cue are perceived as positive when evaluating the quality of the products (Alex \& Abraham, 2015). However, researchers still differ whether or not COO is used by consumers to judge a product. On the one hand, previous research showed that $\mathrm{COO}$ activates country specific stereotypes, which are automatic and show a cognitive and affective impact comparable to a halo-effect on the product (Herz \& D iamantopoulis, 2012). Other research demonstrated that consumers are willing to pay a higher price for a particular product depending on the origin of the traders (Hu \& Wang, 2010). O'Mara et al. (2011) also reported that COO serves as a proxy for risk reduction of the purchase in situations where relevant information is missing or unknown.
Opposite to this, a study on fast-consuming products in India showed that $\mathrm{COO}$ cues do not have a cognitive use and are even ignored for product evaluation (Alex \& Abraham, 2015). Further, Samiee et al. (2005) concluded that consumers do not remember COO as relevant information for product evaluation. Liefeld (2004) proved that consumers do not use the $\mathrm{COO}$ as an information cue when making product evaluations, and Balabanis and Diamantopoulos (2008) found that consumers have little knowledge about the country of origin of the products.

The influence of $\mathrm{COO}$ on consumers'evaluations has been investigated in many countries (Sin, Ho \& So, 2000; Bailey \& Pineres, 1997; Ghazali et al., 2008; Lin \& Chen, 2006; Haque et al., 2015; Dagger \& Raciti, 2011; Alex \& Abraham, 2015). Product differentiation and labeling with a "made in" symbol have also been discussed in Switzerland for nearly one decade (Bravermann, 2007); however, the Swiss market needs further research. Swiss products have an excellent reputation both at home and abroad. They are considered to be reliable and of high quality and the economic added value of their Swiss origin is used by Swiss and international companies (Casanova, 2007). According to the results of a survey over $60 \%$ of Swiss respondents are ready to pay more than the double for products produced in Switzerland (Bundesamt für Landwirtschaft, 2007).

Since there is so much disagreement about whether COO has an effect or not and there is no much research with the Swiss market, this study aims to extend previous research on COO cue utilization by testing the use of visual symbols on Swiss and German consumers and its influence on product judgement. Specifically, the study investigates whether the Swiss flag has an effect on consumer behavior and product evaluation.

(1) Department of Psychology, Europäische Fernhochschule Hamburg, Germany

(2) Department of Psychology, Universidad de la Costa, Barranquilla, Colombia

(3) Department of Industrial Engineering, Universidad Simón Bolívar, Barranquilla, Colombia

(4) Markus Herzberg, RACERFISH, Zürich, Switzerland

*Corresponding author: olga.visbal@euro-fh.de

ISSN: 0718-2724. (http://jotmi.org)

Journal of Technology Management \& Innovation (c) Universidad Alberto Hurtado, Facultad de Economía y Negocios. 
Another important point to be considered is that the products shown in this study are not typical from Switzerland, but just branded with the Swiss flag. Previous studies on COO have used the term as either the origin of the product (the country of production) or the origin of the brand (home country of the brand). Research has confirmed that consumers use both $\mathrm{COO}$ definitions to make inferences about the quality of the product (Johnson, Tian, \& Lee, 2016). According to Johnson et al. (2016), the "country of origin fit" plays a meaningful role in the evaluation of products. The country of origin fit refers to whether the product and brand origin are the same. In the opposite situation where the country of the product and the brand are different, then there is no country of origin fit. Sangwon, Zachary, and Xin (2009) demonstrated that the country of origin fit leads to a more positive evaluation of the product than no fit. Products shown in this research are not typical from Switzerland, but just branded with the Swiss flag and therefore with a low COO fit.

Consumer knowledge about the product is also an important factor that influences the COO cues (Chiou, 2003; Mahswaran, 1994). Consumer knowledge refers to the consumers' experiences related to the product, which has an influence on product evaluation (Alba \& Hutchinson, 1987). Brand familiarity is one of these consumer knowledge dimensions. Being familiar with a brand or product implies that no additional information will be used to evaluate the product. Accordingly, unfamiliar brands will lead to product evaluations based on COO cues (Alex \& Abraham, 2015). This study used fictitious and therefore unfamiliar brands and consequently we expect that $\mathrm{COO}$ cues will influence product evaluation.

Previous studies have also demonstrated that demographic variables like age (Bailey \& Pineres, 1997; Huddleston et al., 2001), gender (Sharma et al., 1995), the level of education (Insch \& McBride, 2004) have an influence on the $\mathrm{COO}$ effect. According to this, consumers' demographic characteristics may influence the way they perceive and evaluate products. Therefore investigation should focus on the identification of further demographic variables that influence the $\mathrm{COO}$ effect.

Since the variables associated with the evaluation consumers make on a product are diverse, the primary goal of this investigation was to examine the influence of visual symbols on the perception and evaluation of two fictitious products. Although there is no country of origin fit in this study, the authors assume that the COO will have an effect on product evaluation. Also, the study investigates a further demographic characteristic and its influence on the COO effect. The specific goals were: a) to examine the influence of COO cues (Swiss flag) on the evaluation (acceptance and quality of the product) of two unfamiliar products with low COO fit with Swiss and German consumers and; b) to analyze the effect of participants' nationality on product evaluation.

\section{Method}

\section{Participants}

The sample consisted of 373 participants ( $47 \%$ men and 53\% women) with ages ranging from 18 to $83(M=39.03, S D=14.44)$. Regarding nationality, (51\%) were Swiss, (46\%) German and (3\%) had another nationality. The participants in our study were recruited using a nonrandom sampling procedure through the research panel ResearchNow, social networks (Xing, LinkedIn, and Facebook) and through the online campus of a German distance learning university.

\section{Design}

\section{Independent variables}

Stimulus materials were developed by a graphic designer and included two products: a rice package and a toothpaste tube (see Figures $1,2,3 \& 4)$. The products did not have any specific brand marks or details that participants could recall to avoid the influence of existing brands and make them unfamiliar to the participants. The pictures of the products were identical and differed only in the visual Swiss symbol (Swiss flag).

Figure 1. Rice package without Swiss symbol

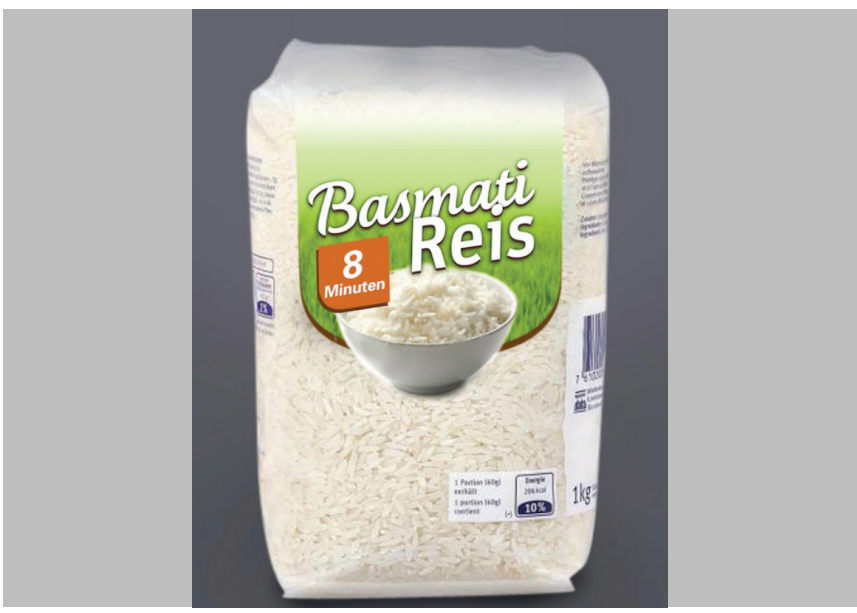

Figure 2. Rice package with Swiss symbol

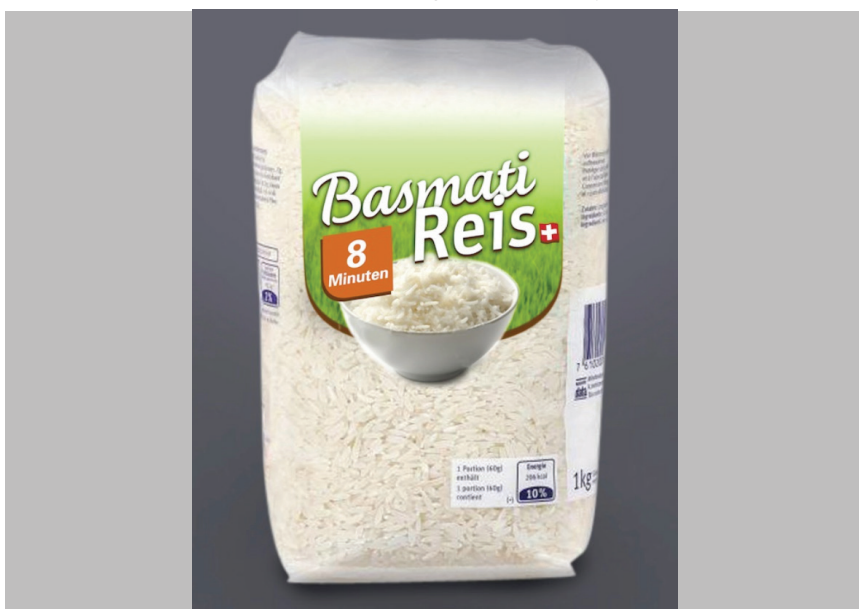


Figure 3. Toothpaste tube without Swiss symbol

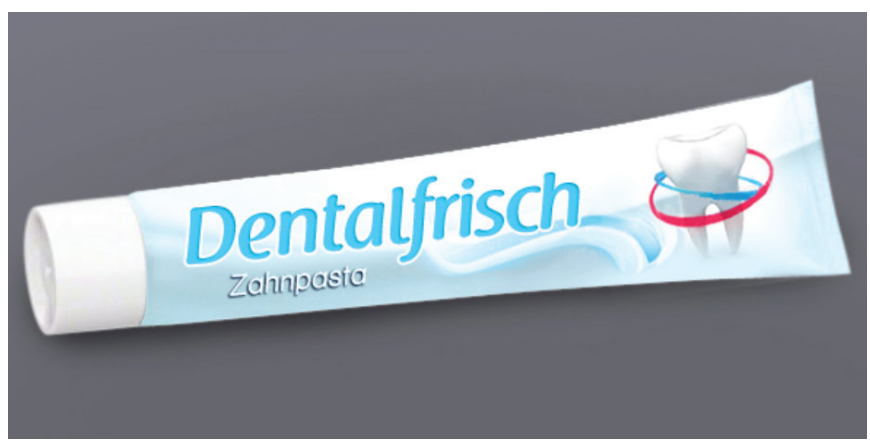

Figure 4. Toothpaste tube with Swiss symbol



Dependent variables

To assess participants' attitudes towards the products, the study used two methods. The first method was the semantic differential scale, which we administered as described in Bortz and Döring (2005). Eight of the 25 items were adapted to the purpose of this study, and an additional item was added (see Table 1). The scale consists of 26 bipolar adjective pairs. Participants evaluated the products on a 7-point scale.

Table 1

Semantic differential with 26 bipolar adjective pairs

\begin{tabular}{l}
\hline Adjective Pairs \\
\hline Tender / hard \\
Bright / sad \\
Cheap / expensive \\
Strong / weak \\
Generous / thrifty \\
Eco-friendly / wastful \\
Passive / active \\
Playful / serious \\
Conservative / open \\
Helpful / selfish \\
Traditional / modern \\
Exclusive / average \\
High-tech / old-fashioned \\
Peaceful / aggressive \\
Chaotic / structured \\
Quiet / loud \\
Strict / flexible \\
Robust / tender \\
Reasonable / discontented \\
Wild / sanft \\
Innovative / uninspired \\
Fresh / tired \\
Reliable / unstable \\
High-quality / inferior \\
Shy / sociable \\
\hline
\end{tabular}

Source: Authors
The second method was the Self-Assessment Manikin (SAM, see Figure 5), which measures the affective dimensions valence, arousal, and dominance associated with the products (Morris, 1995). Participants were asked to rate their affective reaction to the products on a 9-point scale. Both scales are useful for measuring affective responses and complement each other (verbal vs. nonverbal measurement). It has also been shown that both scales hold the same dimensional structure (Osgood et al., 1957) and are highly correlated (Bradley \& Lang, 1994).

Figure 5. Self-Assessment Manikin (SAM)

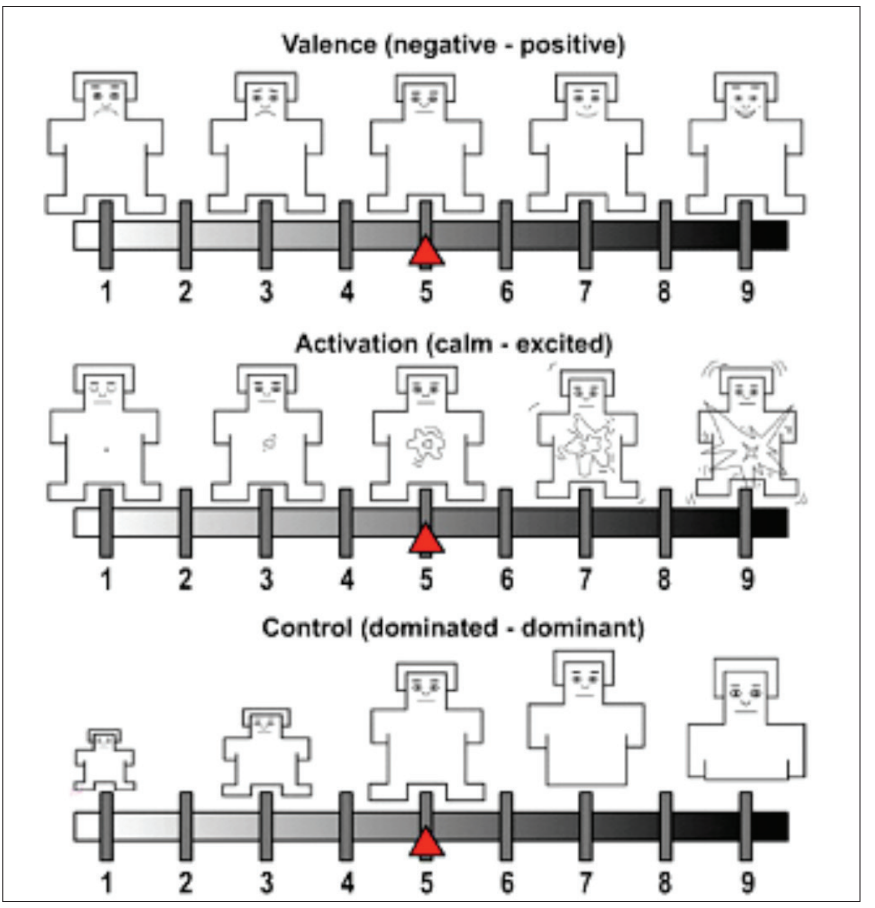

Furthermore, participants were asked to estimate the price $(\mathrm{CHF}$ or EUR), the acceptance and the quality of the products: "How do you estimate the quality of the product?" Participants responded on a 7-point scale with endpoints labeled very bad/very good, "Do you know the product?," "Have you already bought and consumed the product?," "Would you buy and consume the product?". They also rated how ecologically friendly the product is (7-point scale with the point labels very little and very strong), how the price-quality relationship is and if the products meet their expectations; both items on a 7-point scale with the labels very bad/very good.

\section{Demographic variables}

Participants reported background information like gender, age, place of residence and nationality (these two variables were limited to Germany, Switzerland, Austria and other).

\section{Procedure}

The questionnaire was first pretested by administering it to a Swiss sample $(\mathrm{N}=33)$. The results of the pretest showed that the selected items were appropriate for the purpose of the study. Moreover, the pretest confirmed the results of past studies (Osgood et al., 1957; 
Bradley \& Lang, 1994). According to factor analyses, the items of both scales loaded into similar factors. No changes were needed after pretesting.

The final questionnaire was developed with SoSci Survey (online tool), which automatically randomized participants into two conditions (products with flag/products without flag). Participants were assigned to one of the two experimental conditions (products with the Swiss symbol or products without the Swiss symbol). The first condition included Figures 2 and 4, the second condition included Figures 1 and 3. The link was distributed over 11 days on ResearchNow, social networks and the online campus of a German distance learning university. Participants then completed the questionnaire.

\section{Results}

\section{Reliability}

A Kolmogorov-Smirnov test was used to test for normality on the main dependent variables for both products. The percentage on the semantic differential D (373) $=0.42, \mathrm{p}<.05$, and the SAM D (373) $=3.77, \mathrm{p}<.05$, were both significantly non-normal. Because of this, non-parametric tests were used to analyze the data. Both scales had good reliabilities SAM $\alpha=.75$ SemDiff $\alpha=.90$.

\section{Factor Analysis}

Initially, a principal component factor analysis with varimax rotation was conducted on the 26 semantic differential items for both products to assess dimensionality of the constructs and identify unreliable items. The Kaiser-Meyer-Olkin measure confirmed the sampling adequacy for the analysis .80 for the rice and .75 for the toothpaste, which is above the recommended value of .6. The Bartlett's test of sphericity was significant for both products: rice $\chi^{2}(66)=1532.83, p<.01$ and toothpaste $\chi^{2}(66)=1525.44, p<.01$. These results confirmed that the correlations between the adjectives were strong enough for PCA. The analyses and eigenvalues revealed that three components were the best option for the final analysis because a) it explained $63 \%$ of the variance and b) of its previous theoretical and research support. Usually, the list of adjective pairs loads onto three factors similar to the dimensions of the SAM (pleasure, arousal, and dominance) (Osgood et al., 1957). To increase the reliability of the scales, some adjectives were removed. Tables 2 and 3 show the factor loadings after rotation. Factor one represents the dimension pleasure, factor two arousal, and factor three dominance.
Table 2

Factor loadings of the adjective pairs for the product Rice

\begin{tabular}{lccc}
\hline & $\begin{array}{c}\text { Factor 1 } \\
\text { "Pleasure" }\end{array}$ & $\begin{array}{c}\text { Factor 2 } \\
\text { “Arousal" }\end{array}$ & $\begin{array}{c}\text { Factor3 } \\
\text { "Dominance" }\end{array}$ \\
\hline exclusive/average &. $\mathbf{7 8 9}$ & -.079 & -.137 \\
high-tech/old-fashioned & .770 & -.104 & .006 \\
innovative/uninspired & .840 & -.013 & -.058 \\
fresh/tired & .692 & .381 & -.133 \\
high-quality/inferior & .774 & .235 & .125 \\
peaceful/aggressive & -.039 & .782 & -.143 \\
reasonable/discontented & .096 & .776 & .039 \\
quiet/loud & -.289 & $\mathbf{. 6 5 4}$ & -.235 \\
reliable/unstable & .338 & .749 & .097 \\
soeber/dreamy & -.475 & .307 &. $\mathbf{5 0 9}$ \\
strict/flexible & -.137 & -.104 &. $\mathbf{7 6 9}$ \\
robust/tender & .102 & -.123 & $\mathbf{. 7 9 1}$ \\
\hline
\end{tabular}

Source: Authors

Table 3

Factor loadings of the adjective pairs for the product Toothpaste Tube

\begin{tabular}{lccc}
\hline & $\begin{array}{c}\text { Factor 1 } \\
\text { "Pleasure" }\end{array}$ & $\begin{array}{l}\text { Factor 2 } \\
\text { “Arousal" }\end{array}$ & $\begin{array}{l}\text { Factor3 } \\
\text { "Dominance" }\end{array}$ \\
\hline Bright/sad & $\mathbf{. 5 7 8}$ & .492 & -.022 \\
Strong/weak & $\mathbf{. 6 4 6}$ & .164 & .396 \\
Exclusive/average & .744 & -.242 & -.198 \\
High-tech/old-fashioned & .790 & -.118 & -.066 \\
Innovative/uninspired & .837 & -.063 & -.147 \\
Fresh/tired & .589 & .448 & .084 \\
Peaceful/aggressive & -.050 & .775 & -.279 \\
Reasonable/discontented & .146 & .748 & .238 \\
Quiet/loud & -.353 & .635 & -.214 \\
Soeber/dreamy & -.364 & .423 &. $\mathbf{5 3 7}$ \\
Strict/flexible & -.074 & -.170 & .799 \\
Robust/tender & .017 & -.057 & $\mathbf{. 8 1 3}$ \\
\hline
\end{tabular}

Source: Authors

\section{Main Analyses}

Differences between the groups

There was a significant association between the type of visual stimuli (with or without Swiss flag) and the emotions associated with both products. Results of SAM ratings show significant differences for the rice in the arousal dimension $\chi^{2}(1)=4.86, p<.05$. Results for the toothpaste indicate a significant difference for the dimension pleasure $\chi^{2}(1)=3.97, p=.05$ and the dimension dominance $\chi^{2}(1)=3.98$, $\mathrm{p}=.05$. Additionally, the item "How ecologically friendly is the product?" revealed a significant difference for both products between the groups $\chi^{2}(1)=4.18, p=.05$. 
The results of the semantic differential show only significant differences between the groups for the toothpaste product. There were significant differences for factor one of the semantic differential (pleasure) $\chi^{2}(1)=4.08, \mathrm{p}<.05$.

\section{Effect of the nationality}

A Kruskal-Wallis test was conducted to test the effect of nationality as a covariate. Results in Table 4 show a significant difference for the first factor "pleasure" of the semantic differential for the product rice $H(2)=20,6263, p<.01$ as well as for the first factor "pleasure" $H(2)=9,0783, p<0.01$ and the second factor "arousal" of the toothpaste $H(2)=7,2346, p<0.05$. Mann-Whitney $\mathrm{U}$ test was used to follow up this finding between Germans and Swiss participants, because these were the only ones that showed a positive difference. After applying the Bonferroni correction, all effects are reported at .0167 level of significance. It appears that nationality influenced the effect of the $\mathrm{COO}$ cue on the product evaluation for the first factor "pleasure" for the product rice $(U=11897, r=-0,2316)$ and the first factor "pleasure" ( $U=13272, r=-0,1585)$ and second factor "arousal" of the toothpaste $(U=13617, r=-0,1402)$. The same analyses were conducted for the SAM scale (see Table 5). Results show significant effects on all factors of the SAM scale for the rice product "pleasure" $H(2)=7,1453, p<0.05$, "arousal" $H(2)=9,3493, p<0.01$ and "dominance" $H(2)=19,1077, p<0.01$. Post hoc analyses show significant results "pleasure" $(U=13729, r=-0,1383)$, "arousal" $(U=13292$, $r=-0,1016)$ and "dominance" $(U=12545, r=-0,2021)$. It can be concluded that Swiss participants made significantly more positive associations with the product than other nationalities.

Table 4

Effects of nationality on product evaluation (Sem. Diff)

\begin{tabular}{|c|c|c|c|c|c|c|}
\hline \multirow[b]{2}{*}{ Statistic } & \multicolumn{3}{|c|}{ Rice } & \multicolumn{3}{|c|}{ Toothpaste } \\
\hline & $\begin{array}{c}\text { Factor } \\
1\end{array}$ & $\begin{array}{c}\text { Factor } \\
2\end{array}$ & $\begin{array}{c}\text { Factor } \\
3\end{array}$ & $\begin{array}{c}\text { Factor } \\
1\end{array}$ & $\begin{array}{c}\text { Factor } \\
2\end{array}$ & $\begin{array}{c}\text { Factor } \\
3\end{array}$ \\
\hline Chi-square ${ }^{a}$ & 20,6263 & 4,5281 & 0,5752 & 9,0783 & 7,2346 & 0,2433 \\
\hline df & 2,0000 & 2,0000 & 2,0000 & 2,0000 & 2,0000 & 2,0000 \\
\hline Sig. & 0,0000 & 0,1039 & 0,7501 & 0,0107 & 0,0269 & 0,8855 \\
\hline $\begin{array}{l}\text { Mann- } \\
\text { Whitney }\end{array}$ & 11897 & 14326 & 15721 & 13272 & 13617 & 15777 \\
\hline Wilcoxon W & 29852 & 29204 & 33676 & 31227 & 28495 & 33732 \\
\hline Z & $-4,3999$ & $-1,9470$ & $-0,5382$ & $-3,0116$ & $-2,6631$ & $-0,4817$ \\
\hline Sig. & 0,0000 & 0,0515 & 0,5904 & 0,0026 & 0,0077 & 0,6300 \\
\hline Effect ( $\mathrm{r}$ ) & $-0,2316$ & $-0,1025$ & $-0,0283$ & $-0,1585$ & $-0,1402$ & $-0,0254$ \\
\hline
\end{tabular}

a. Kruskal Wallis Test
Table 5

Effects of nationality on product evaluation (SAM)

\begin{tabular}{lcccccc}
\hline & \multicolumn{3}{c}{ Rice } & \multicolumn{3}{c}{ Toothpaste } \\
\cline { 2 - 7 } Statistic & Pleasure & Arousal & $\begin{array}{c}\text { Domi- } \\
\text { nance }\end{array}$ & Pleasure & Arousal & $\begin{array}{c}\text { Domi- } \\
\text { nance }\end{array}$ \\
\hline $\begin{array}{l}\text { Chi- } \\
\text { square a }\end{array}$ & 7,1453 & 9,3493 & 19,1077 & 3,7407 & 2,0162 & 2,9910 \\
df & 2,0000 & 2,0000 & 2,0000 & 2,0000 & 2,0000 & 2,0000 \\
Sig. & 0,0281 & 0,0093 & 0,0000 & 0,1541 & 0,3649 & 0,2241 \\
\hline $\begin{array}{l}\text { Mann- } \\
\text { Whitney }\end{array}$ & 13729 & 13292 & 12545 & 14541 & 14896 & 14564 \\
$\begin{array}{l}\text { Wilcoxon } \\
\text { W }\end{array}$ & 28607 & 28170 & 27423 & 29419 & 29774 & 29442 \\
Z & $-2,6272$ & $-3,0418$ & $-3,8407$ & $-1,7856$ & $-1,3939$ & $-1,7345$ \\
Sig. & 0,0086 & 0,0024 & 0,0001 & 0,0742 & 0,1634 & 0,0828 \\
$\begin{array}{l}\text { Effect } \\
\text { r })\end{array}$ & $-0,1383$ & $-0,1601$ & $-0,2021$ & $-0,0940$ & $-0,0734$ & $-0,0913$ \\
\hline
\end{tabular}

Kruskal Wallis Test

\section{Discussion}

The present study investigated the influence of visual symbols on product evaluation using two different methods: a semantic differential and the self-assessment manikin. The results reveal differences between the groups. Thus, the products with the Swiss flag were associated with more positive emotions (pleasure, arousal, and dominance) as compared to the products without the Swiss flag. Furthermore, both products with the Swiss flag were rated as more eco-friendly as compared to the products without the Swiss flag. This corroborated Jacoby's et al. (1971) cue utilization theory, which postulates that consumers make deductions about the quality of the product based on cues like a flag. This is also consistent with previous research (Alex \& Abraham, 2015), which clearly indicates that consumers perceived certain brands with the "made in" label cue as positive when evaluating the product. It is important to mention that the products with the Swiss flag were associated with more positive emotions although the COO fit low was. According to Sangwon, Zachary, \& Xin (2009), the country of origin fit leads to a more positive evaluation of the product than no fit. Opposite to the findings of (Sangwon, Zachary, \& Xin, 2009), in this study participants made positive associations (positive emotions or described products as eco-friendly) although the country of production and the country of origin (low COO fit) were different. Further research is needed to follow up these results and see if products with a high COO fit (like Swiss watches or Swiss chocolates) will lead to more and stronger positive associations with the products.

A social psychological explanation for these results is the activation of specific stereotypes, which are automatically associated with the products when participants see the Swiss flag. The activation of country related stereotypes seems to have an impact comparable to a haloeffect on the product. The halo-effect is that one stereotype associated with the country (i.e. good quality) will overlap all other attributes of the product. Studies on this topic are consistent with this assumption (Herz \& Diamantopoulis 2012). 
Moreover, the results showed that the participant's nationality influenced the effect of the Swiss flag on the product evaluation. Swiss nationality increased the positive evaluations compared to other nationalities. It seems that national pride and familiarity with the Swiss flag cue increases the effect. This is not surprising because in Switzerland, almost every business uses a Swiss symbol cue on the products and that Swiss people prefer products from their home country (Bundesamt für Landwirtschaft, 2007). Marketing experts are convinced of this fact and consider it an effective "unwritten law". Further research should investigate the effect of Swiss national pride on Swiss product evaluation. It was also observed that the product rice obtained more significant effects than the toothpaste. The data indicates that Swiss participants believed to have already bought and consumed the fictitious rice. This could explain why rice was preferred and obtained more positive evaluations as compared to the toothpaste. A psychological explanation for this is the availability heuristic (Tversky \& Kahneman, 1973). A better and quicker availability of the product (I have already bought and consumed the product) is considered as own information. Therefore, the recipient has the feeling that he is more familiar with the product and classifies it as a relevant and highquality one. Research about consumer knowledge about the product (i.e. brand familiarity) implies that such consumer knowledge will lead to an evaluation of the product without additional information like CCO cues (Alex \& Abraham, 2015). Although both products were completely fictitious, Swiss participants believed to have bought and consumed the rice previously, which in turn lead to a better evaluation of the product.

A follow up to investigate the effect of other nationalities and the consumer knowledge about the product will be interesting. Further research should investigate which processes lead to a positive association with the product. Is it due to the activation of country stereotypes or due to the national identity?

Investigating how consumers' make purchase decisions and what influences their attitudes towards a product is very important for understanding and predicting consumers' behavior. The results of this study cannot be generalized, but they definitively expand and support previous knowledge on $\mathrm{COO}$ cues and their influence on product perception and evaluation as well as the influence of demographic characteristics on $\mathrm{COO}$ effect.

\section{References}

Alba, J. W., \& Hutchinson, J. W. (1987). Dimensions of consumer expertise. Journal of Consumer Research, 13(4), 411. doi:10.1086/209080

Alex N., J., \& Abraham, A. M. (2015). The role of consumer knowledge dimensions on country of origin effects: An Enquiry of fast-consuming product in India. Vision: The Journal of Business Perspective, 19(1), 1-12. doi:10.1177/0972262914564040

Bailey, W., \& Pineres, S. A. G. D. (1997). Country of origin attitudes in Mexico: the malinchismo effect. Journal of International Consumer Marketing, 9(3), 25-41.
Balabanis, G., \& Diamantopoulos, A. (2008). Brand origin identification by consumers: A classification perspective. Journal of International Marketing, 16(1), 39-71. doi:10.1509/jimk.16.1.39

Bortz, J. \& Döring, N. (2005). Forschungsmethoden und Evaluation für Human- und Sozialwissenschaftler. Heidelberg: Springer.

Bradley, M. M. \& Lang, P. J. (1994). Measuring emotion: The Self-Assessment Manikin and the semantic differential. Journal of Behavior Therapy and Experimental Psychiatry, 25(1), 49-59.

Braverman, B. (2007). Swiss brands vote for tougher 'Swiss Made' criteria. National Jeweler, 101(9), 10.

Brodie, R. \& Sharma, R. (2011). The Swiss National Brand. University of Auckland Business Review, 14(1), 16-17.

Bundesamt für Landwirtschaft (2007). Herkunft von Landwirtschaftprodukten. Bern.

Casanova, M. (2007). Die Marke Schweiz: Gefangen in der Mythosfalle zwischen Heidi und Willhelm Tell: Aktuelle Herausforderungen im Zusammenhang mit der Verwendung der Marke Schweiz als CoBranding-Partner. In Psychologie der Markenführung (pp.531-539). Verlag Franz Vahlen GmbH.

Chiou, J. (2003). The impact of country of origin on pretrial and posttrial product evaluations: The moderating effect of consumer expertise. Psychology and Marketing, 20(10), 935-954. doi:10.1002/ mar.10103

Dagger, T. S., \& Raciti, M. M. (2011). Matching consumers' country and product image perceptions: an Australian perspective. Journal of Consumer Marketing, 28(3), 200-210.

Ghazali, M., Othman, M. S., Yahya, A. Z., \& Ibrahim, M. S. (2008). Products and country of origin effects: The Malaysian consumers' perception. International Review of Business Research Papers, 4(2), 91-102.

Haque, A., Anwar, N., Yasmin, F., Sarwar, A., Ibrahim, Z., \& Momen, A. (2015). Purchase intention of foreign products: A study on Bangladeshi consumer perspective. SAGE Open, 5(2), 2158244015592680.

Herz, M. F., \& Diamantopoulos, A. (2012). Activation of country stereotypes: Automaticity, consonance, and impact. Journal of the Academy of Marketing Science, 41(4), 400-417. doi:10.1007/s11747012-0318-1

Hu, Y., \& Wang, X. (2010). Country-of-origin premiums for retailers in international trades: evidence from eBay's international markets. Journal of Retailing, 86(2), 200-207.

Huddleston, P., Good, L. K., \& Stoel, L. (2001). Consumer ethnocentrism, product necessity and Polish consumers' perceptions of quality. International Journal of Retail \& Distribution Management, 29(5), 236-246. 
Insch, G. S., \& McBride, J. B. (2004). The impact of country-of-origin cues on consumer perceptions of product quality: A binational test of the decomposed country-of-origin construct. Journal of Business Research, 57(3), 256-265.

Jacoby, J., Olson, J. C., \& Haddock, R. A. (1971). Price, brand name, and product composition characteristics as determinants of perceived quality. Journal of Applied Psychology, 55(6), 570-579. doi:10.1037/ h0032045

Johnson, Z. S., Tian, Y., \& Lee, S. (2016). Country-of-origin fit: When does a discrepancy between brand origin and country of manufacture reduce consumers' product evaluations? Journal of Brand Management, 23(4), 403-418. doi:10.1057/bm.2016.13

Koschate-Fischer, N., Diamantopoulos, A., \& Oldenkotte, K. (2012). Are consumers really willing to pay more for a favorable country image? A study of country-of-origin effects on willingness to pay. Journal of International Marketing, 20(1), 19-41. doi: http://dx.doi. org/10.1509/jim.10.0140

Liefeld, J. P. (2004). Consumer knowledge and use of country-of-origin information at the point of purchase. Journal of Consumer Behaviour, 4(2), 85-87.

Lin, L. Y., \& Chen, C. S. (2006). The influence of the country-of-origin image, product knowledge and product involvement on consumer purchase decisions: an empirical study of insurance and catering services in Taiwan. Journal of Consumer Marketing, 23(5), 248-265.

Maheswaran, D. (1994). Country of origin as a stereotype: Effects of consumer expertise and attribute strength on product evaluations. Journal of Consumer Research, 21(2), 354. doi:10.1086/209403

Maheswaran, D., \& Chen, C. Y. (2006). Nation equity: Incidental emotions in country-of-origin effects. Journal of Consumer Research, 33(3), 370-376.
Miller, J. W. (2011). Country labeling sets off EU debate. The Wall Street Journal. Retrieved from https://www.wsj.com/articles/ SB100014240527487040626045761056916229225\%2076.html

Morris, J. D. (1995). Observations: SAM: The self-assessment manikin: An efficient cross-cultural measurement of emotional response. Journal of Advertising Research, 35(6), 63-68.

O’Mara, K., Cort, K., \& Palin, G. (2011). A cross-national empirical study investigating the role of purchasing purpose has on the country-of-origin-effect. International Journal of the Academic Business World, 5(1), 99-108.

Osgood, C., Suci, G., \& Tannenbaum, P. (1957). The measurement of meaning. Urbana, IL: University of Illinois.

Samiee, S., Shimp, T. A., \& Sharma, S. (2005). Brand origin recognition accuracy: Its antecedents and consumers' cognitive limitations. Journal of International Business Studies, 36(4), 379-397. doi:10.1057/ palgrave.jibs. 8400145

Sangwon, L., Zachary, J., \& Xin, H. (2009). Brand origin or product origin? The effects of country of origin Fit on brand evaluation. NA Advances in Consumer Research, 36, 1013-1014.

Sharma, S., Shimp, T. A., \& Shin, J. (1995). Consumer ethnocentrism: A test of antecedents and moderators. Journal of the Academy of Marketing Science, 23(1), 26-37.

Sin, L. Y., Ho, S. C., \& So, S. L. (2000). Research on advertising in mainland China: a review and assessment. Asia Pacific Journal of Marketing and Logistics, 12(1), 37-65.

Tversky, A. \& Kahneman, D. (1973). Availability: A heuristic for judging frequency and probability. Cognitive Psychology, 5, 207-232. 
